\title{
COMPARATIVE STUDY OF DIAGNOSTIC EFFICACY OF FNAC, HR-USG \& MAMMOGRAPHY IN PALPABLE BREAST LUMP
}

\author{
Shadab Asif' ${ }^{1}$, Anand Vardhan ${ }^{2}$, Saleem Tahir ${ }^{3}$, Mohammad Amir ${ }^{4}$, Saurabh Singh ${ }^{5}$, Mayanka Singh ${ }^{6}$, Amir Afroz $^{7}$, Avaneesh Tiwari ${ }^{8}$ \\ ${ }^{1}$ Assistant Professor, Department of General Surgery, Era's Lucknow Medical College and Hospital, Lucknow, Uttar Pradesh, India. \\ ${ }^{2} 3^{\text {rd }}$ Year Junior Resident, Department of General Surgery, Era's Lucknow Medical College and Hospital, Lucknow, Uttar Pradesh, India. \\ 3 Professor, Department of General Surgery, Era's Lucknow Medical College and Hospital, Lucknow, Uttar Pradesh, India. \\ 4 Senior Resident, Department of General Surgery, Era's Lucknow Medical College and Hospital, Lucknow, Uttar Pradesh, India. \\ 53rd Year Junior Resident, Department of General Surgery, Era's Lucknow Medical College and Hospital, Lucknow, Uttar Pradesh, India. \\ ${ }^{6} 3^{\text {rd }}$ Year Junior Resident, Department of General Surgery, Era's Lucknow Medical College and Hospital, Lucknow, Uttar Pradesh, India.

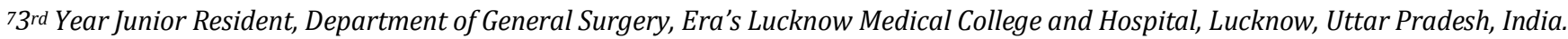 \\ ${ }^{83}$ rd Year Junior Resident, Department of Internal Medicine, Era's Lucknow Medical College and Hospital, Lucknow, Uttar Pradesh, \\ India.
}

\section{BACKGROUND}

\section{ABSTRACT}

With growing awareness and increasing literacy, people have now become more conscious about problems related to breast. The commonest mode of presentation of diseases of the breast is "lump" or a "palpable mass". It may not necessarily be a malignant lesion, instead palpable breast masses are common and are usually benign, but efficient evaluation and prompt diagnosis are necessary to rule out malignancy. The present study was planned with an aim to evaluate the efficacy of HR-USG, Mammography and FNAC, either individually or in combination for the diagnosis of palpable breast lumps.

\section{MATERIALS AND METHODS}

The descriptive study was carried out at Department of Surgery, Era's Lucknow Medical College, Lucknow. Duration of study was 18 months starting from January 2017 to June 2018. A total of 65 patients were enrolled in the study who underwent HR-USG, FNAC, Mammography and Histopathological examination.

\section{RESULTS}

In present study, majority of cases were histopathologically confirmed as benign (69.2\%). Among benign cases, maximum ( $\mathrm{n}=37$; $56.9 \%)$ were diagnosed as fibroadenoma, $4(6.2 \%)$ were diagnosed as simple benign lesion and $3(4.6 \%)$ were diagnosed as chronic inflammatory lesion. There were 21 (30.8\%) malignant cases, for malignancy, FNAC had a sensitivity and specificity of $90 \%$ and $100 \%$ as compared to $76.2 \%$ and $100 \%$ for mammography and $71.4 \%$ and $97.7 \%$ for USG.

\section{CONCLUSION}

The findings of the present study suggest that among three diagnostic modalities being evaluated, FNAC was the best, but one of the limitations of FNAC was inconclusive findings in few cases. However, complementary use of USG for these cases which were inconclusive on FNAC helped to achieve the best diagnostic combination for evaluation of palpable lump.

\section{BACKGROUND}

With growing awareness and increasing literacy, people have now become more conscious towards problems related with breast. The commonest mode of presentation of diseases of the breast is "lump" or a "palpable mass." It may not necessarily be a malignant lesion, instead palpable breast masses are common and usually benign, but efficient evaluation and prompt diagnosis are necessary to rule out malignancy. In order to provide the patient an optimal treatment, it is essential to carry out an accurate preoperative diagnosis.
\end{abstract}

HOW TO CITE THIS ARTICLE: Asif S, Vardhan A, Tahir S, et al. Comparative study of diagnostic efficacy of FNAC, HR-USG \& mammography in palpable breast lump. J. Evolution Med. Dent. Sci. 2019;8(13):1027-1035, DOI: 10.14260/jemds/2019/228

'Financial or Other Competing Interest': None.

Submission 19-01-2019, Peer Review 18-03-2019,

Acceptance 23-03-2019, Published 01-04-2019.

Corresponding Author:

Dr. Shadab Asif,

\#592K/34, Subhani Khera,

Telibagh, Lucknow-226002, Uttar Pradesh, India.

E-mail: dranandkds@gmail.com

DOI: $10.14260 /$ jemds $/ 2019 / 228$

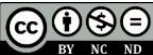

A single-modality test is not accurate enough to make the correct diagnosis for a breast lesion. However, the accuracy of the diagnosis can be increased by employing multimodality tests. A number of modalities together are more accurate and reliable compared to a single-modality test, despite having their own technical limitations.

However, in recent years, ultrasonography has emerged as an effective diagnostic tool in evaluation of palpable solid breast masses. The diagnostic accuracy of mammography and USG has been seen to be increased when used in combination. ${ }^{1}$

Fine-needle aspiration is fast, inexpensive, and accurate, and it can differentiate solid and cystic masses.

Thus, all the three diagnostic tests have their usefulness in evaluation of palpable breast lesions, however, it is often queried that in view of emerging improvements in technology, particularly with the emergence of digital mammography, improved methods of FNAC and highresolution USG, whether the number of these tests could be reduced, or the combination of these tests could be altered. Hence, the present study was planned with an aim to evaluate the efficacy of HR-USG, Mammography and FNAC, either 
individual or in combination for diagnosis of Palpable breast lumps.

\section{MATERIALS AND METHODS}

The aim of this study was to compare the diagnostic efficacy of HR-USG, FNAC and mammography in early diagnosis of patients presenting with palpable breast lump to outpatient department of General Surgery, Era's Lucknow Medical College \& Hospital, Lucknow.

The study was designed as descriptive study to be conducted over a period of 18 months.

After obtaining an informed consent, demographic information and details regarding breast complaints, like lump, nipple discharge or retraction were noted.

All participants were subjected to clinical examination,

HR-USG, Mammography, FNAC and histopathological reporting according to study protocol.

\section{Sample Size Calculation}

\section{RESULTS}

A total of 65 women with palpable breast lumps were enrolled in the study.

\section{Lump Characteristics}

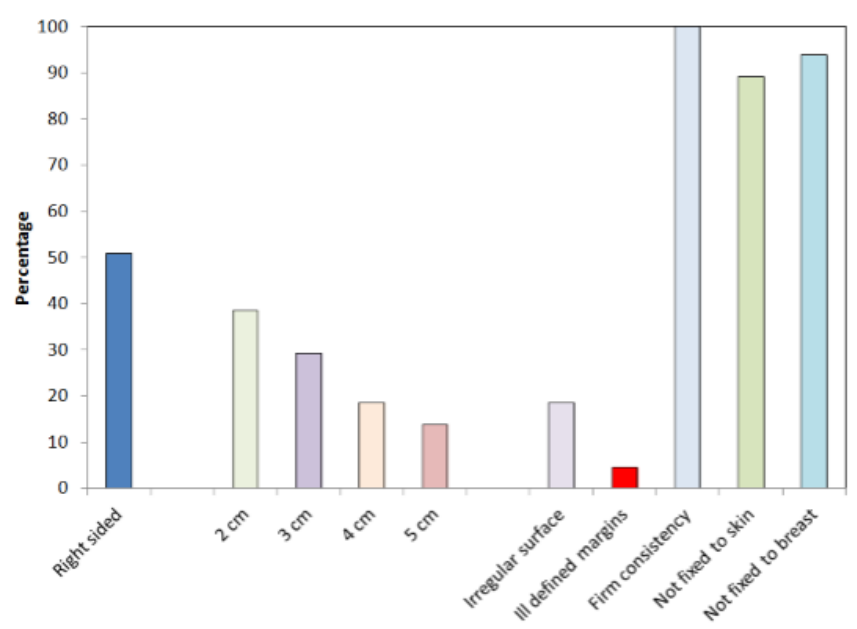

Figure 1. Lump Characteristics

Right side (50.8\%) was slightly more commonly involved than the left side (49.2\%). Maximum had lump with a size of $2 \mathrm{~cm}$ (38.5\%) followed by $3 \mathrm{~cm}(29.2 \%), 4 \mathrm{~cm}(18.5 \%)$ and $5 \mathrm{~cm} \mathrm{(13.8 \% )} \mathrm{respectively.} \mathrm{Majority} \mathrm{(81.5 \% )} \mathrm{had} \mathrm{smooth} \mathrm{surface} \mathrm{while} 12$ (18.5\%) had irregular surface of lump. Except for 3 (4.6\%), all the other cases had well defined lump margins. All the lumps had firm consistency. None of the cases showed lump fluctuation or transillumination. In majority lump was not fixed to skin (89.2\%) or breast (93.8\%). None of the cases showed fixity to deeper structure or axilla and supraclavicular fossa involvement.

\section{Histopathological Examination}


Histopathologically, majority ( $\mathrm{n}=44 ; 69.2 \%)$ were diagnosed as non-malignant. However, $21(30.8 \%)$ were diagnosed as malignant. Among non-malignant lumps, maximum ( $\mathrm{n}=37 ; 56.9 \%)$ were diagnosed as fibroadenoma, $4(6.2 \%)$ were diagnosed as simple benign lesion and $3(4.6 \%)$ were diagnosed as chronic inflammatory lesion.

\section{Mammography}

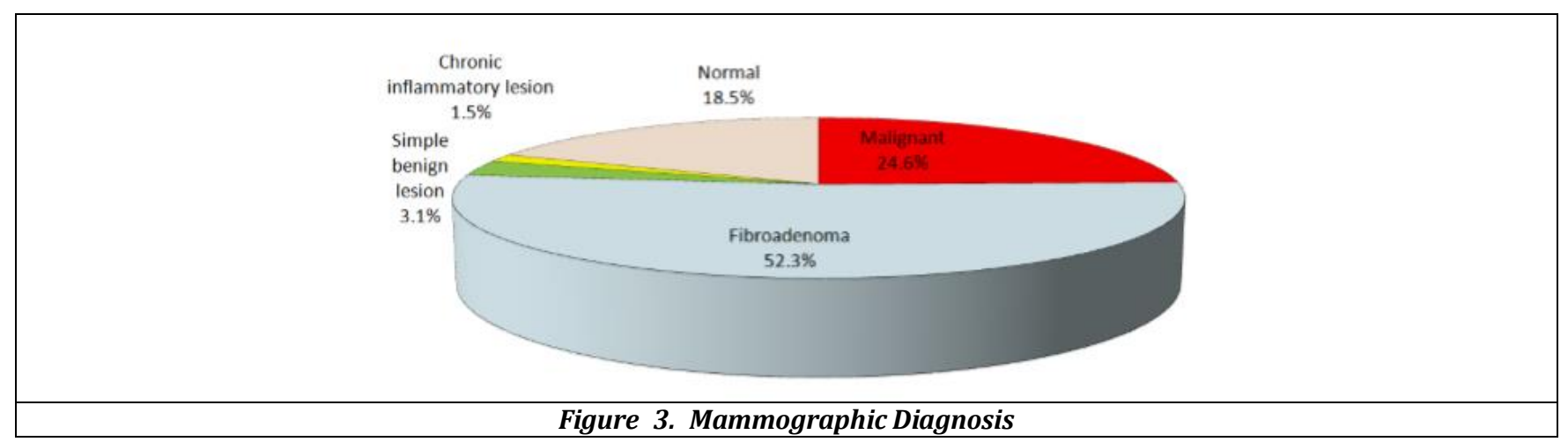

On mammography, majority $(\mathrm{n}=49 ; 75.4 \%)$ were diagnosed as non-malignant. However, $16(24.6 \%)$ were diagnosed as malignant. Among non-malignant lumps, maximum ( $\mathrm{n}=34 ; 52.3 \%)$ were diagnosed as fibroadenoma, 2 (3.1\%) were diagnosed as simple benign lesion and $1(1.5 \%)$ was diagnosed as inflammatory lesion. There were $12(18.5 \%)$ cases diagnosed normal on mammography.

\section{High Resolution-Ultrasonography}

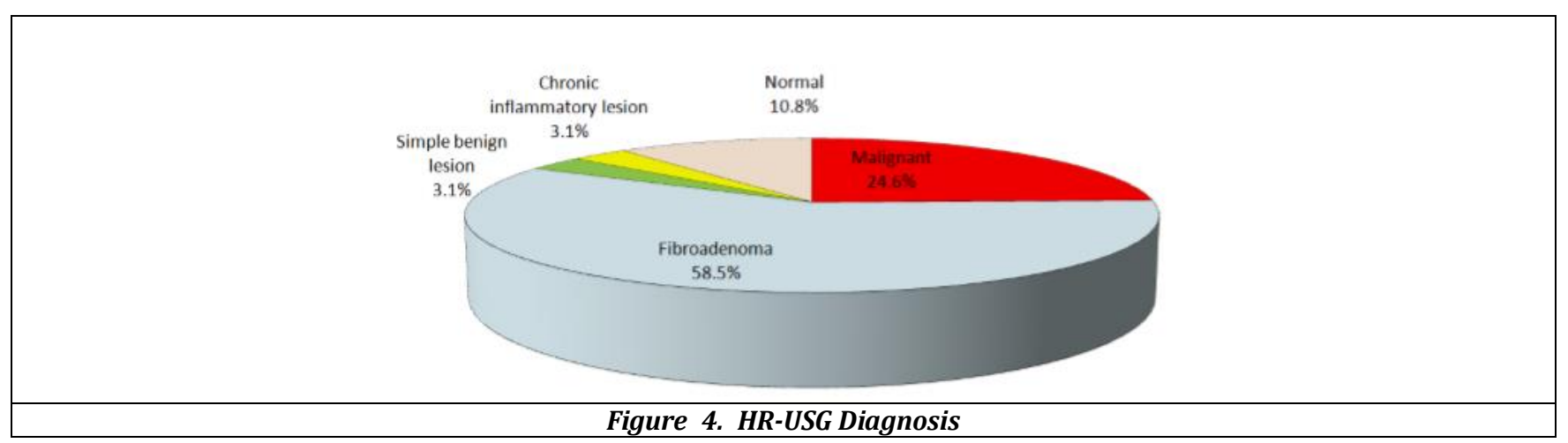

On HR-USG, majority ( $\mathrm{n}=49 ; 75.4 \%)$ were diagnosed as non-malignant. However, 16 (24.6\%) were diagnosed as malignant. Among non-malignant lumps, maximum ( $\mathrm{n}=38 ; 58.5 \%)$ were diagnosed as fibroadenoma, 2 (3.1\%) each were diagnosed as simple benign lesion and inflammatory lesion respectively while 7 (10.8\%) cases were diagnosed as normal on USG.

\section{Fine Needle Aspiration Cytology}

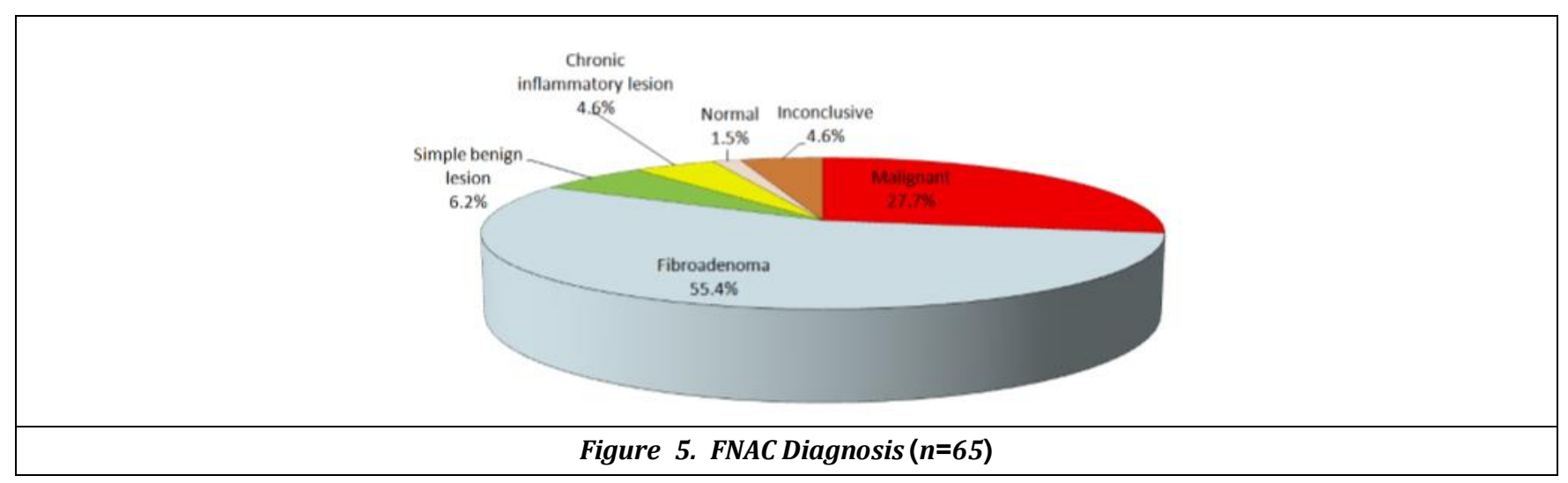

On FNAC, majority $(\mathrm{n}=44 ; 67.7 \%)$ were diagnosed as non-malignant. However, $18(27.7 \%)$ were diagnosed as malignant. Among non-malignant lumps, maximum ( $\mathrm{n}=36 ; 55.4 \%)$ were diagnosed as fibroadenoma, $4(6.2 \%)$ were diagnosed as simple benign lesion and $3(4.6 \%)$ as inflammatory lesion. There was $1(1.5 \%)$ case diagnosed as normal. FNAC was inconclusive in 3 (4.6\%) cases. 


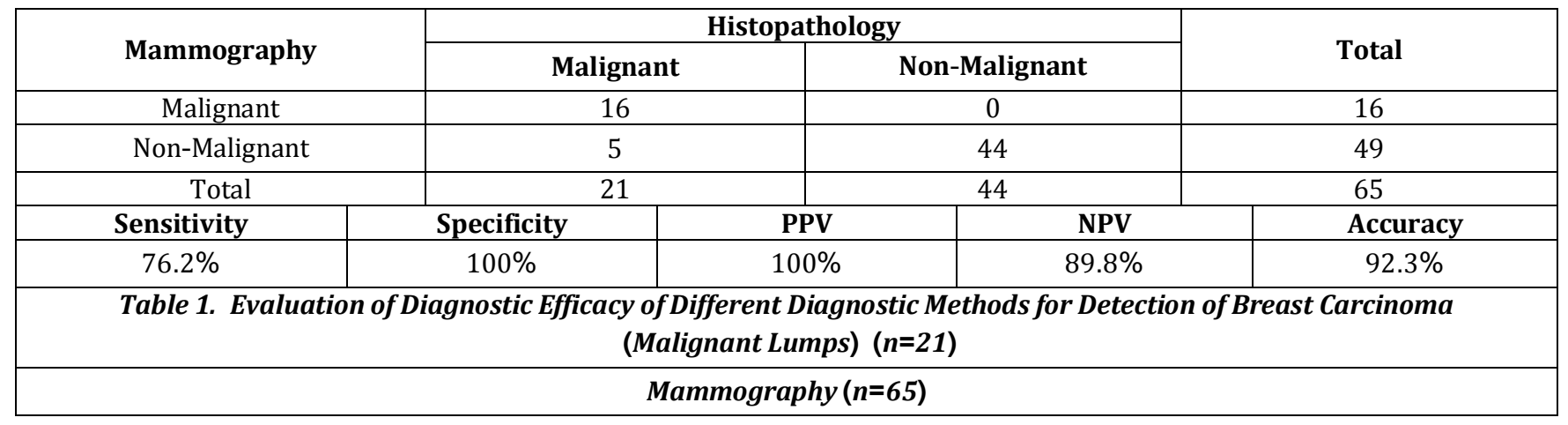

\begin{tabular}{|c|c|c|c|c|}
\hline \multirow{2}{*}{ Ultrasonography } & \multicolumn{3}{|c|}{ Histopathology } & \multirow{2}{*}{ Total } \\
\hline & \multicolumn{2}{|l|}{ Malignant } & Non-Malignant & \\
\hline Malignant & \multicolumn{2}{|l|}{15} & 1 & 16 \\
\hline Non-Malignant & \multicolumn{2}{|l|}{6} & 43 & 49 \\
\hline Total & 21 & & 44 & 65 \\
\hline Sensitivity & Specificity & PPV & NP & Accuracy \\
\hline $71.4 \%$ & $97.7 \%$ & $93.8 \%$ & & $89.2 \%$ \\
\hline \multicolumn{5}{|c|}{ Ultrasonography $(n=65)$} \\
\hline
\end{tabular}

\begin{tabular}{|c|c|c|c|c|}
\hline \multirow{2}{*}{ FNAC } & \multicolumn{3}{|c|}{ Histopathology } & \multirow{2}{*}{ Total } \\
\hline & \multicolumn{2}{|c|}{ Malignant } & Non-Malignant & \\
\hline Malignant & \multicolumn{2}{|c|}{18} & 0 & 18 \\
\hline Non-Malignant & \multicolumn{2}{|c|}{2} & 42 & 44 \\
\hline Total & \multicolumn{2}{|c|}{20} & 42 & 62 \\
\hline Sensitivity & Specificity & PPV & NP & Accuracy \\
\hline $90.0 \%$ & $100 \%$ & $100 \%$ & 95.5 & $96.8 \%$ \\
\hline \multicolumn{5}{|c|}{ (c) FNAC $(n=62)$} \\
\hline
\end{tabular}

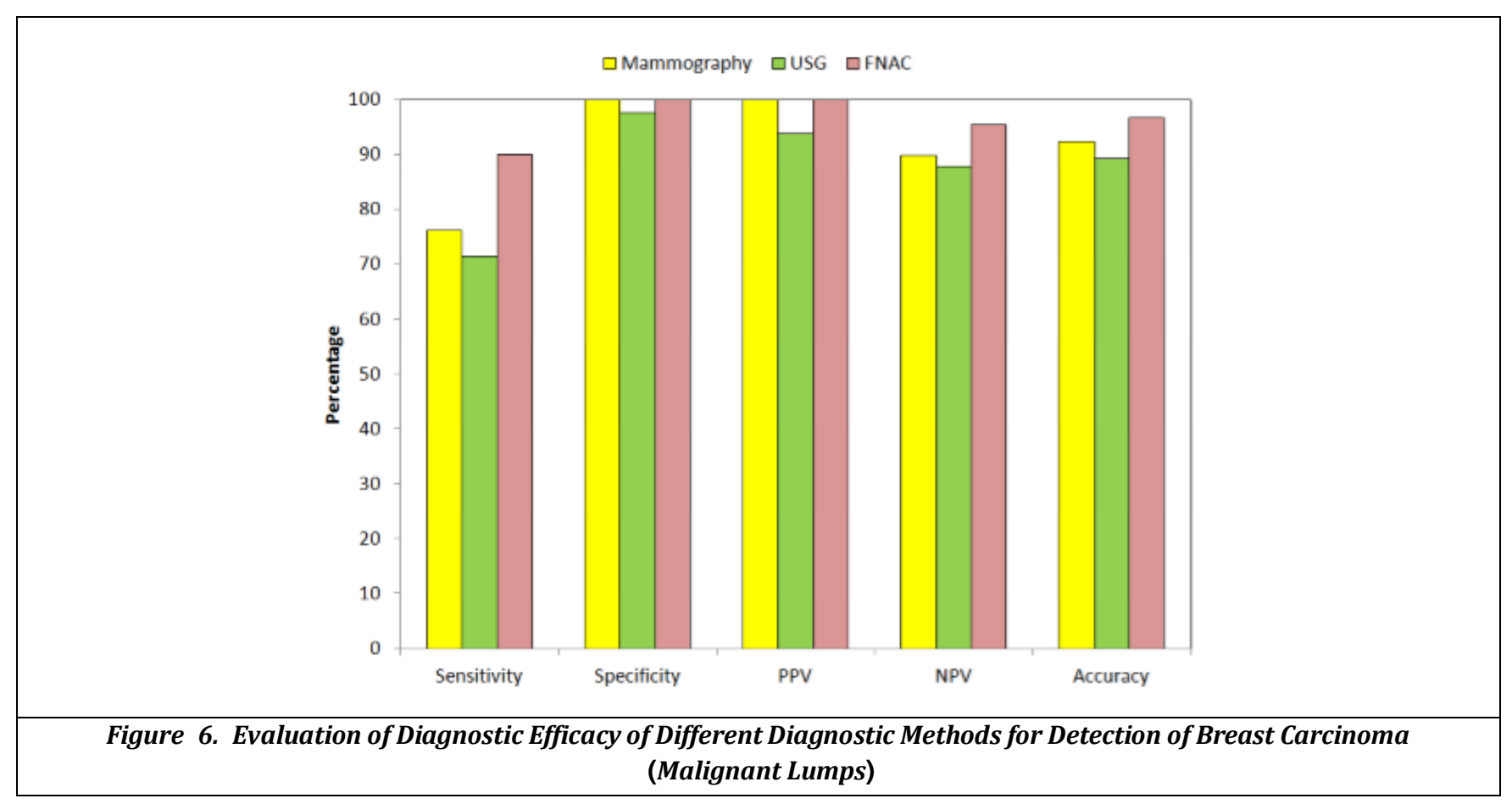

On evaluating the diagnostic efficacy of mammography, ultrasonography and FNAC for detection of malignancy, sensitivity and specificity of FNAC was maximum (90\% and 100\%). Between mammography and USG, mammography was more sensitive as well as specific (76.2\% and 100\%) as compared to USG (71.4\% and 97.7\%). Both mammography and FNAC had $100 \%$ positive predictive value as compared to $93.8 \%$ for USG. With respect to negative predictive value, FNAC had maximum value (95.5\%) followed by Mammography $(89.8 \%)$ and USG $(87.8 \%)$ respectively. Overall accuracy for detection of malignancy was also maximum for FNAC (96.8\%) followed by mammography (92.3\%) and USG $(89.2 \%)$ respectively. 


\begin{tabular}{|c|c|c|c|c|}
\hline \multirow{2}{*}{ Mammography } & \multicolumn{3}{|c|}{ Histopathology } & \multirow{2}{*}{ Total } \\
\hline & \multicolumn{2}{|c|}{ Fibroadenoma } & Others & \\
\hline Fibroadenoma & \multicolumn{2}{|c|}{31} & 3 & 34 \\
\hline \multirow{2}{*}{$\begin{array}{c}\text { Others } \\
\text { Total }\end{array}$} & \multicolumn{2}{|c|}{5} & 26 & 31 \\
\hline & \multicolumn{2}{|c|}{36} & 29 & 65 \\
\hline Sensitivity & Specificity & PPV & NPV & Accuracy \\
\hline $86.1 \%$ & $89.7 \%$ & $91.2 \%$ & $83.9 \%$ & $87.7 \%$ \\
\hline \multicolumn{5}{|c|}{ Table 2. Evaluation of Diagnostic Efficacy of Different Diagnostic Methods for Detection of Fibroadenoma ( $n=36$} \\
\hline \multicolumn{5}{|c|}{ Mammography $(n=65)$} \\
\hline
\end{tabular}

\begin{tabular}{|c|c|c|c|c|}
\hline \multirow{2}{*}{ USG } & \multicolumn{3}{|c|}{ Histopathology } & \multirow{2}{*}{ Total } \\
\hline & \multicolumn{2}{|c|}{\begin{tabular}{l|l} 
Fibroadenoma & \\
\end{tabular}} & Others & \\
\hline Fibroadenoma & \multicolumn{2}{|c|}{32} & 6 & 38 \\
\hline Others & \multicolumn{2}{|c|}{4} & 23 & 27 \\
\hline Total & \multicolumn{2}{|c|}{36} & 29 & 65 \\
\hline Sensitivity & Specificity & PPV & NPV & Accuracy \\
\hline $88.9 \%$ & $79.3 \%$ & $84.2 \%$ & $85.2 \%$ & $84.6 \%$ \\
\hline \multicolumn{5}{|c|}{ (b) $U S G(n=65)$} \\
\hline
\end{tabular}

\begin{tabular}{|c|c|c|c|}
\hline \multirow{2}{*}{ USG } & \multicolumn{2}{|c|}{ Histopathology } & \multirow{2}{*}{ Total } \\
\hline & Fibroadenoma & Others & \\
\hline Fibroadenoma & 34 & 2 & 36 \\
\hline \multirow{2}{*}{$\begin{array}{c}\text { Others } \\
\text { Total }\end{array}$} & 2 & 24 & 26 \\
\hline & 36 & 26 & 62 \\
\hline Sensitivity & Specificity & NPV & Accuracy \\
\hline $94.4 \%$ & $92.3 \%$ & $92.3 \%$ & $93.5 \%$ \\
\hline \multicolumn{4}{|c|}{ (c) FNAC $(n=62)$} \\
\hline
\end{tabular}

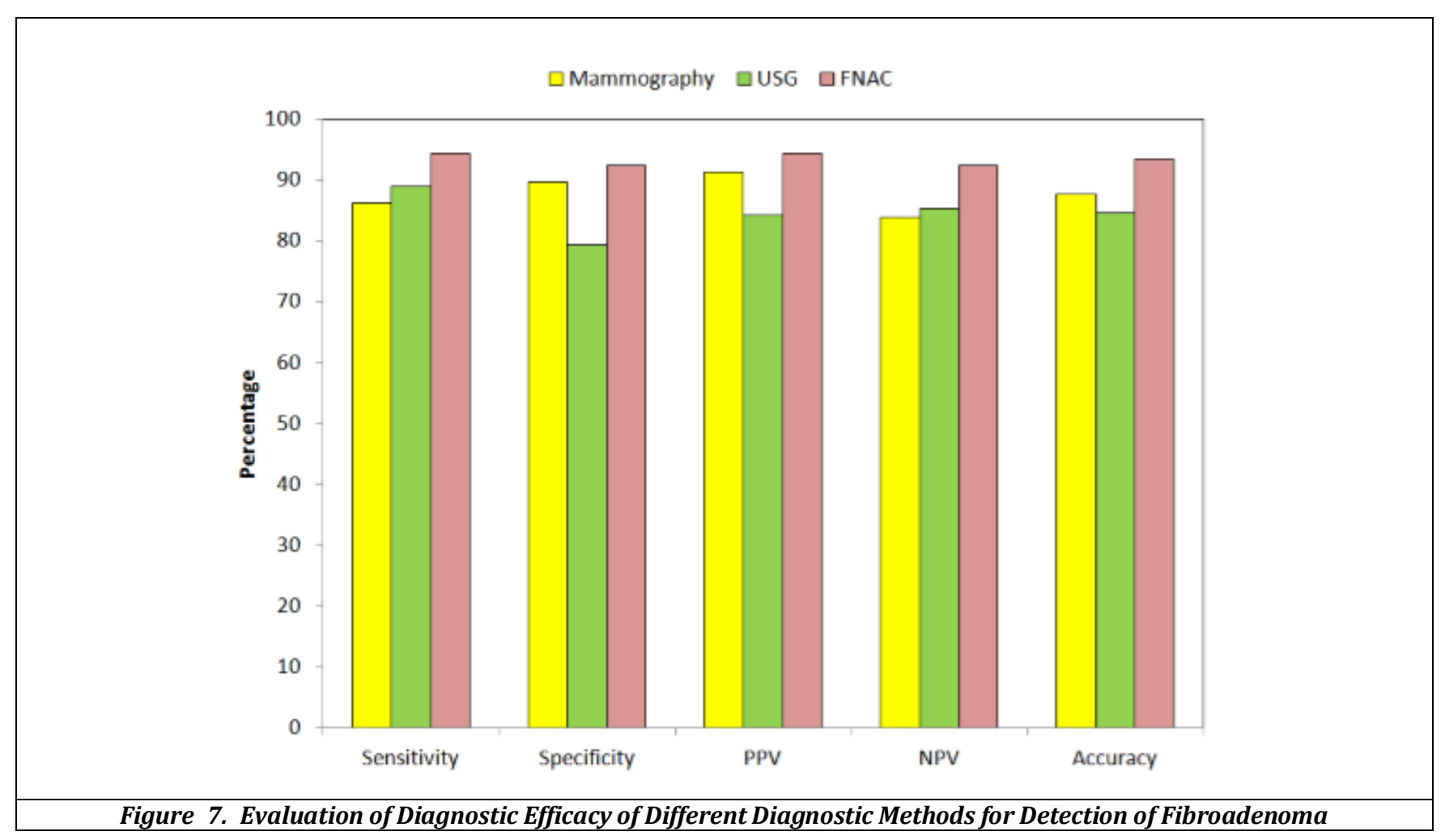

On evaluating the diagnostic efficacy of mammography, ultrasonography and FNAC for detection of fibroadenoma, sensitivity and specificity of FNAC was maximum (94.4\% and 92.3\%). Between mammography and USG, USG was more sensitive (88.9\%) as compared to mammography (86.1\%) while mammography was more specific (89.7\%) as compared to USG (79.3\%). FNAC also had maximum PPV and NPV (94.4\% and 92.3\%). Between mammography and USG, mammography had higher PPV (91.2\%) as compared to USG (84.2\%) whereas USG had higher NPV (85.2\%) as compared to mammography (83.9\%). Overall accuracy for detection of fibroadenoma was maximum for FNAC (93.5\%) followed by mammography (87.7\%) and USG (84.6\%) respectively. 


\begin{tabular}{|c|c|c|c|c|}
\hline \multirow{2}{*}{ Mammography } & \multicolumn{3}{|c|}{ Histopathology } & \multirow{2}{*}{ Total } \\
\hline & \multicolumn{2}{|c|}{\begin{tabular}{|l|l} 
Simple Benign lesion &
\end{tabular}} & Others & \\
\hline Simple Benign lesion & \multicolumn{2}{|l|}{2} & 0 & 2 \\
\hline Others & \multicolumn{2}{|l|}{2} & 61 & 63 \\
\hline Total & 4 & \multirow[b]{2}{*}{$\begin{array}{l}\text { PPV } \\
\end{array}$} & 61 & 65 \\
\hline Sensitivity & Specificity & & NPV & Accuracy \\
\hline $50 \%$ & $100 \%$ & $100 \%$ & $95.3 \%$ & $96.9 \%$ \\
\hline \multicolumn{5}{|c|}{ Table 3. Evaluation of Diagnostic Efficacy of Different Diagnostic Methods for Detection of Simple Benign Lesions ( $n=$} \\
\hline \multicolumn{5}{|c|}{ Mammography $(n=65)$} \\
\hline
\end{tabular}

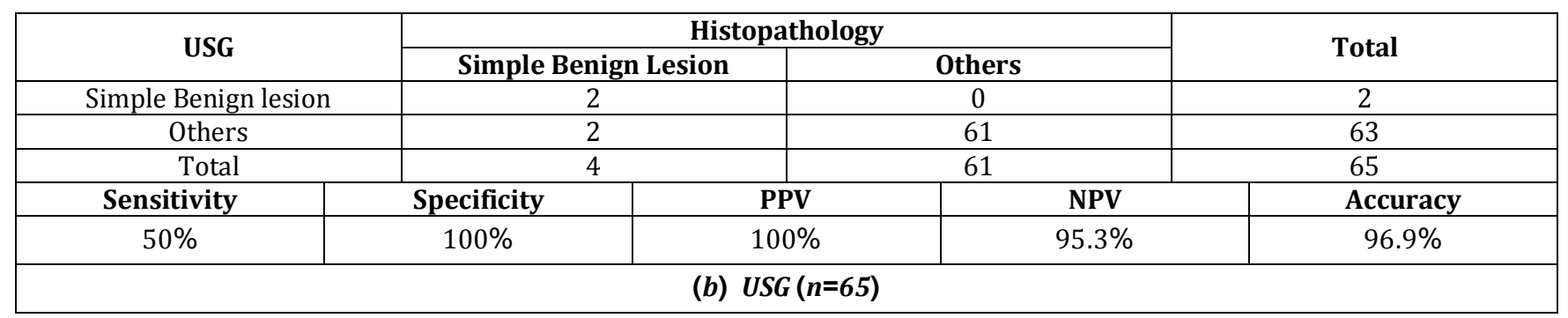

\begin{tabular}{|c|c|c|c|c|}
\hline \multirow{2}{*}{ USG } & \multicolumn{3}{|c|}{ Histopathology } & \multirow{2}{*}{ Total } \\
\hline & \multicolumn{2}{|l|}{ Simple Benign lesion } & Others & \\
\hline Simple Benign lesion & \multicolumn{2}{|l|}{4} & 0 & 4 \\
\hline Others & \multicolumn{2}{|l|}{0} & 58 & 58 \\
\hline Total & 4 & \multirow[b]{2}{*}{ PPV } & \multirow[t]{2}{*}{58} & 62 \\
\hline Sensitivity & Specificity & & & Accuracy \\
\hline $100 \%$ & $100 \%$ & $100 \%$ & $100 \%$ & $100 \%$ \\
\hline \multicolumn{5}{|c|}{ (c) FNAC $(n=62)$} \\
\hline
\end{tabular}

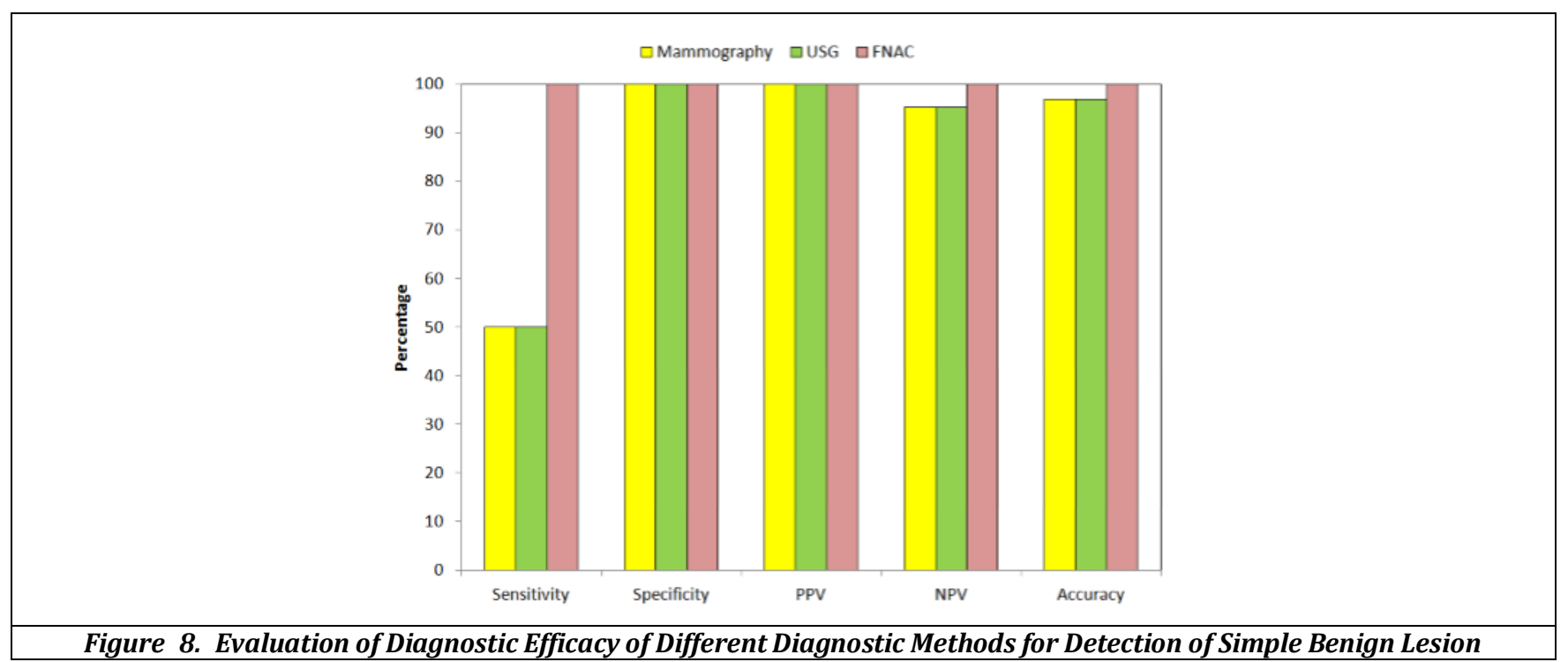

On evaluating the diagnostic efficacy of mammography, ultrasonography and FNAC for detection of simple benign lesion, FNAC showed $100 \%$ accuracy. Both USG and mammography same showed sensitivity, specificity, PPV, NPV and accuracy, i.e. 50\%, 100\%, $100 \%, 95.3 \%$ and $96.9 \%$ respectively.

\begin{tabular}{|c|c|c|c|c|}
\hline \multirow{2}{*}{ Mammography } & \multicolumn{3}{|c|}{ Histopathology } & \multirow{2}{*}{ Total } \\
\hline & \multicolumn{2}{|c|}{\begin{tabular}{|l|l|} 
Inflammatory lesion & \\
\end{tabular}} & Others & \\
\hline Inflammatory Lesion & \multicolumn{2}{|c|}{1} & 0 & 1 \\
\hline Others & \multicolumn{2}{|c|}{2} & 62 & 64 \\
\hline Total & \multicolumn{2}{|c|}{3} & 62 & 65 \\
\hline Sensitivity & Specificity & PPV & NPV & Accuracy \\
\hline $33.3 \%$ & $100 \%$ & $100 \%$ & $96.9 \%$ & $96.9 \%$ \\
\hline \multicolumn{5}{|c|}{ Table 4. Evaluation of Diagnostic Efficacy of Different Diagnostic Methods for Detection of Inflammatory Lesions ( $n=3$} \\
\hline \multicolumn{5}{|c|}{$\operatorname{Mammography}(n=65)$} \\
\hline
\end{tabular}




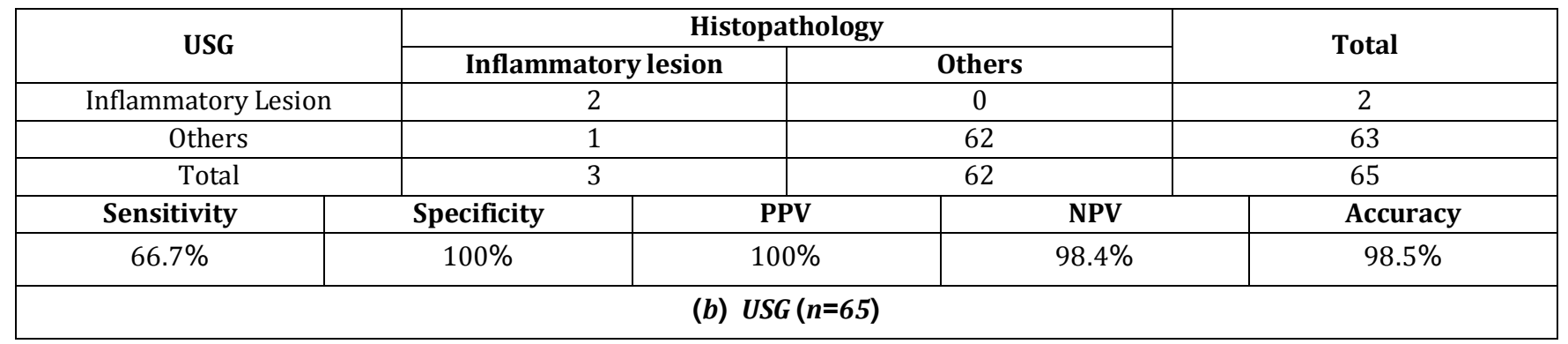

\begin{tabular}{|c|c|c|c|c|}
\hline \multirow{2}{*}{ USG } & \multicolumn{3}{|c|}{ Histopathology } & \multirow{2}{*}{ Total } \\
\hline & \multicolumn{2}{|c|}{ Inflammatory Lesion } & Others & \\
\hline Inflammatory Lesion & \multicolumn{2}{|c|}{3} & 0 & 3 \\
\hline Others & \multicolumn{2}{|c|}{0} & 59 & 59 \\
\hline Total & \multicolumn{2}{|c|}{3} & 59 & 62 \\
\hline Sensitivity & Specificity & PPV & NPV & Accuracy \\
\hline $100 \%$ & $100 \%$ & $100 \%$ & $100 \%$ & $100 \%$ \\
\hline \multicolumn{5}{|c|}{ (c) $\operatorname{FNAC}(n=62)$} \\
\hline
\end{tabular}

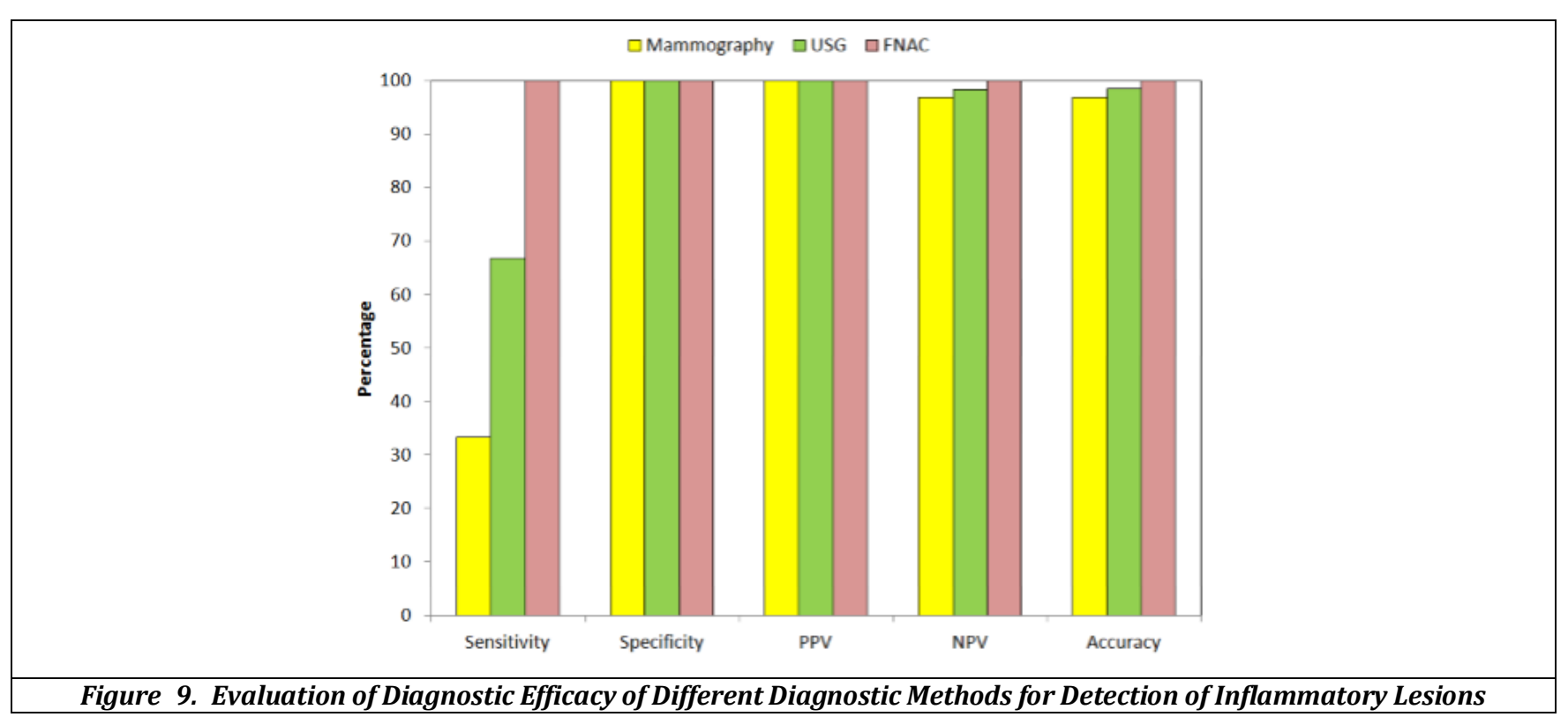

On evaluating the diagnostic efficacy of mammography, ultrasonography and FNAC for detection of inflammatory lesions, FNAC showed 100\% accuracy. Between USG and mammography, both were $100 \%$ specific, however, USG was more sensitive $(66.7 \%)$ as compared to mammography $(33.3 \%)$. In terms of accuracy FNAC was best $(100 \%)$ followed by USG (98.5\%) and mammography (96.9\%) respectively.

\section{DISCUSSION}

In present study, majority of cases were histopathologically confirmed as benign (69.2\%). Among benign cases, maximum $(n=37 ; 56.9 \%)$ were diagnosed as fibroadenoma, $4(6.2 \%)$ were diagnosed as simple benign lesion and $3(4.6 \%)$ were diagnosed as chronic inflammatory lesion. There were 21 (30.8\%) malignant cases. Similar to findings of present study, previous studies too have reported a dominance of benign conditions and malignancy to be a dormant finding. In study of Rahman et al. ${ }^{2}$ and Khoda et al. ${ }^{1}$ the malignancy rate was $28.6 \%$ and $24 \%$. Taori et al. $^{3}$ and Khan et al. ${ }^{4}$ reported malignancy rate of $18.1 \%$ and $18.7 \%$ respectively. Nigam and Nigam 5 found malignancy in only $10 \%$ cases. The findings of present study were comparable to the findings of Takhellambam et al. ${ }^{6}$ and Harini et al. ${ }^{7}$ Who reported a malignancy rate of $35.5 \%$ and $30.3 \%$ cases respectively which is close to the observations made in present study. As for dominance of fibroadenoma in benign cases, it is probably the most common benign breast condition encountered in different studies.8,9,10,11,12,13 In their study, Tiwari et al. in their final diagnosis found $17 \%$ cases as carcinoma, $41.5 \%$ fibrocystic disease, $28.3 \%$ fibroadenoma, $5.7 \%$ cysts, $3.7 \%$ infection and $1.9 \%$ lipoma.

In present study, on mammography, majority $(n=49$; $75.4 \%$ ) were diagnosed as non-malignant. However, 16 $(24.6 \%)$ were diagnosed as malignant. Among non-malignant lumps, maximum ( $\mathrm{n}=34 ; 52.3 \%)$ were diagnosed as fibroadenoma, $2(3.1 \%)$ were diagnosed as simple benign lesion and $1(1.5 \%)$ was diagnosed as inflammatory lesion. There were 12 (18.5\%) cases diagnosed normal on mammography. In their study, Tiwari et al.14 on mammography found malignancy in $15.1 \%$, fibrocystic disease in $34 \%$, fibroadenoma in $22.6 \%$, cyst in $3.7 \%$, and infection and lipoma in $1.9 \%$ case each. Thus, similar to present study, they also found malignancy rate to be lower in 
mammography as compared to final diagnosis. Chaudhari et al. ${ }^{15}$ too in their study found detection of malignancy to be lower in mammography (46\%) as compared to histopathology (62\%). Similar observations were also made by other workers too. $2,3,5,14$

In present study, on USG, majority $(\mathrm{n}=49 ; 75.4 \%)$ were diagnosed as non-malignant. However,15 (24.6\%) were diagnosed as malignant. Among non-malignant lumps, maximum $(\mathrm{n}=38 ; 58.5 \%)$ were diagnosed as fibroadenoma, 2 (3.1\%) each were diagnosed as simple benign lesion and inflammatory lesion respectively while $7(10.8 \%)$ cases were diagnosed as normal on USG. Thus, similar to mammography, USG also underestimated malignancy while overestimated the fibroadenoma cases slightly. However, Tiwari et al. in their study found malignancy detection rate to be lower in USG as compared to mammography as well as final diagnosis. Chaudhari et al.15 similar to our finding reported the malignancy detection rate in USG to be lower as compared to final diagnosis. Although, they overestimated the benign conditions in general but did not describe the profile of benign conditions separately and hence we are not in a position to comment whether they particularly overestimated fibroadenoma.

In present study, on FNAC, majority $(\mathrm{n}=44 ; 67.7 \%)$ were diagnosed as non-malignant. However, 18 (27.7\%) were diagnosed as malignant. Among non-malignant lumps, maximum $(n=36 ; 55.4 \%)$ were diagnosed as fibroadenoma, 4 (6.2\%) were diagnosed as simple benign lesion and $3(4.6 \%)$ as inflammatory lesion. There was $1(1.5 \%)$ case diagnosed as normal. FNAC was inconclusive in $3(4.6 \%)$ cases. Thus, compared to mammography and USG, the detection rate for malignancy was higher in FNAC whereas for fibroadenoma it underestimated but did not underestimate to the extent of mammography. In most of the studies reviewed by us, detection rate of malignancy has been reported to be high and close to final diagnosis. ${ }^{2,6,5}$ However, Khoda et al. ${ }^{1}$ found both USG and FNAC to be comparable in detection of malignancy.

In present study, for malignancy, FNAC had a sensitivity and specificity of $90 \%$ and $100 \%$ as compared to $76.2 \%$ and $100 \%$ for mammography and $71.4 \%$ and $97.7 \%$ for USG, thus among the three FNAC was the best followed by mammography while USG was least sensitive and specific. The superiority of FNAC over USG and mammography has been endorsed by several workers for evaluation of malignancy. Rahman et al. ${ }^{2}$ in their study reported sensitivity and specificity of FNAC to be $97.22 \%$ and $99.46 \%$ as compared to $82.76 \%$ and $90.36 \%$ for mammography. Nigam and Nigam6 in their study reported USG to be $66.7 \%$ sensitive and $100 \%$ specific as compared to FNAC which was $73.3 \%$ sensitive and $100 \%$ specific. However, Khoda et al. ${ }^{1}$ in their study found both USG and FNAC to hold equal sensitivity and specificity (91.6\% and 100\%). In present study, mammography had slight edge over USG in terms of increased sensitivity, however, Kumar et al. ${ }^{16}$ in their study found USG to have better sensitivity and specificity $(92.3 \%$ and $97.29 \%$ ) as compared to mammography $(84.61 \%$ and $94.59 \%)$. But Tiwari et al.17 similar to our study found mammography to be more sensitive and specific as compared to USG in detection of malignancy.
In present study, for different benign conditions, between mammography and USG, USG was more sensitive than mammography whereas mammography was more specific than USG for fibroadenoma. For simple benign lesions, both USG and mammography were 50\% sensitive and 100\% specific, however for inflammatory lesions, USG had better sensitivity and specificity (66.7\% and $100 \%)$ as compared to mammography (33.3\% and 100\%). However, in their study, Prasad and Houserkova found that mammography had an efficiency of $81.8 \%$ as compared to $95.5 \%$ for USG in detecting fibrocystic mastitis while for fibroadenoma, mammography was more efficient $(75 \%)$ as compared to USG (35\%), thus showing that the findings matched for inflammatory conditions only.

One of the limitations of FNAC was inadequacy in three cases owing to which the diagnosis was inconclusive. On histopathology, the diagnosis was carcinoma in one case and fibroadenoma in remaining two cases, these cases were thus missed by FNAC and resulted in loss of diagnosis. However, USG findings in these three cases were consistent with the histopathology, thus showing that combination of USG and FNAC could help in achieving a better diagnosis. Although combination of mammography and USG or all the three techniques to improve diagnostic performance has been reported by several studies previously,18,3,5 however, similar to our observation, some other workers 19,20 have found combination of USG and FNAC to be highly efficient and effective. We feel that combination of one imaging modality (USG) and one cytological assessment (FNAC) could provide the information regarding the morphology as well as cytology and hence can provide a better diagnosis. Moreover, USG can help in compensating the loss of diagnosis in cases where FNAC is inadequate and hence results are inconclusive. In view of the findings of present study, we recommend the use of FNAC in combination with USG for evaluation of breast masses. However, keeping in view the diverse profile of benign and malignant pathologies of breast, it is recommended that further studies on larger sample size must be carried out to confirm and validate the findings of present study.

\section{CONCLUSION}

The present study assessed the usefulness of mammography, ultrasonography and fine needle aspiration cytology in evaluation of palpable breast lump. For this purpose, a total of 65 women with palpable breast lumps were enrolled in the study and were evaluated using the three diagnostic modalities. The outcome was compared against histopathology.

The findings of present study suggested that among three diagnostic modalities being evaluated, FNAC was the best but one of the limitations of FNAC was inconclusive findings in few cases. However, complementary use of USG for these cases inconclusive on FNAC helped to achieve the best diagnostic combination for evaluation of palpable lump. The present study was limited by the sample size; hence, diagnostic values for simple benign lesions and inflammatory lesions which had only a limited representation could be exaggerated and be dependent on incidental findings; hence, further studies on larger sample size are recommended to corroborate the findings of the present study. 


\section{REFERENCES}

[1] Khoda L, Kapa B, Singh KG, et al. Evaluation of modified triple test (clinical breast examination, ultrasonography and fine-needle aspiration cytology) in the diagnosis of palpable breast lumps. J Med Soc 2015;29(1):26-30.

[2] Rahman MZ, Sikder AM, Nabi SR. Diagnosis of breast lump by fine needle aspiration cytology and mammography. Mymensingh Med J 2011;20(4):65864.

[3] Taori K, Dhakate S, Rathod J, et al. Evaluation of breast masses using mammography and sonography as first line investigations. Open Journal of Medical Imaging 2013;3:40-9.

[4] Khan N, Khan S, Kathroo SA. Efficiency of ultrasonography and fine needle aspiration cytology in the diagnosis of breast lumps in a selected population of Jammu and Kashmir. International Journal of Contemporary Medical Research 2016;3(10):2847-50.

[5] Nigam M, Nigam B. Triple assessment of breast - gold standard in mass screening for breast cancer diagnosis. IOSR Journal of Dental and Medical Sciences (IOSR-JDMS) 2013;7(3):1-7.

[6] Takhellambam YS, Lourembam SS, Sapam OS, et al. Comparison of ultrasonography and fine needle aspiration cytology in the diagnosis of malignant breast lesions. J Clin Diagn Res 2013;7(12):2847-50.

[7] Harini G, Shrinivasan S, Chidambaram R, et al. Diagnostic efficacy of combined mammography and ultrasonography in evaluation of breast lesions with pathological correlation and BIRADS assessment. Ind J Basic Appl Res 2016;6(1):790-9.

[8] Khanzada TW, Samad A, Sushel C. Spectrum of benign breast diseases. Pak J Med Sci 2009;25(2):265-8.

[9] Kaur N, Agarwal N, Panwar P, et al. Clinicopathologic profile of benign breast conditions in Indian women: prospective study based on aberrations of normal development and involution classification. World J Surg 2012;36(9):2252-8.

[10] Albasri AM. Profile of benign breast diseases in western Saudi Arabia. An 8-year histopathological review of 603 cases. Saudi Med J 2014;35(12):151720.
[11] Vimal M, Chitra T. Spectrum of benign breast diseases in females of reproductive age group. J Res Med Den Sci 2016;4(2):137-40.

[12] Saraswat B, Vyas A. Clinicopathological profile of benign breast disease at a tertiary care hospital in Western Rajasthan. Global Journal for Research Analysis 2017;6(5):27-9.

[13] Mehboob R, Perveen S, Ahmed N. Spectrum of benign breast lesions in a tertiary care hospital of Lahore. Annals of King Edwards Medical University 2018;24(1):605-9.

[14] Tiwari P, Ghosh S, Agrawal VK. Evaluation of breast lesions by digital mammography and ultrasound along with fine-needle aspiration cytology correlation. J Can Res Ther 2018;14(5):1071-4.

[15] Chaudhari R, Ray S, Shaikh A. Diagnostic approach to palpable breast lump - a quadruple assessment. Int J Science \& Research 2017;6(5):2572-87.

[16] Kumar H, Mehrotra A, Kumar P, et al. Comparative study of mammography and sonography in breast lump with fine needle aspiration cytology correlation. Int J Basic Appl Med Res 2016;5(2):712-22.

[17] Tiwari P, Ghosh S, Agrawal VK. Mammographic and ultrasonographic evaluation of palpable abnormalities of the breast. National J of Community Med 2017;8(1):37-40.

[18] Prasad SN, Houserkova D. A comparison of mammography and ultrasonography in the evaluation of breast masses. Biomed Pap Med Fac Univ Palacky Olomouc Czech Repub 2007;151(2):315-22.

[19] Hardy JR, Powles TJ, Judson I, et al. How many tests are required in the diagnosis of palpable breast abnormalities? Clin Oncol (R Coll Radiol) 1990;2(3):148-52.

[20] Sundresh NJ, Narendran S, Ramanathan M. Modified triple assessment in breast lumps. International Journal of Pharmacology \& Toxicology 2012;2(2):67-9. 